\title{
Impact of Moringa oleifera Cake Residue Application on Waste Water Treatment: A Case Study
}

\author{
N. Ali Eman ${ }^{*}$, C. S. Tan², E. A. Makky² \\ ${ }^{1}$ Faculty of Chemical and Natural Resources Engineering, University Malaysia Pahang, Kuantan, \\ Malaysia \\ ${ }^{2}$ Faculty of Industrial Sciences and Technology, University Malaysia Pahang, Kuantan, Malaysia \\ Email: $\underline{\text { eman@ump.edu.my }}$
}

Received 9 March 2014; revised 5 April 2014; accepted 2 May 2014

Copyright (C) 2014 by authors and Scientific Research Publishing Inc.

This work is licensed under the Creative Commons Attribution International License (CC BY).

http://creativecommons.org/licenses/by/4.0/

(c) (i) Open Access

\begin{abstract}
Most of water treatments require higher expenditure. Chemical coagulant requires higher cost and has some drawback after treatment such as $\mathrm{pH}$ changes. Moringa oleifera cake residue (MOCR) is one of the alternatives to replace chemical coagulant. A jar test apparatus was used to monitor water treatment. Water quality of Gebeng River (GR) and waste water (WW) was examined before and after treatment. Different parameters using (MOCR) was investigated. Preliminary laboratory results showed the great potential of the (MOCR) to be used in water treatment. MOCR shows an excellent reduction in turbidity ( $97 \%$ was removed). The bacteria were reduced from $1.7 \times 10^{5}$ to $8 \times 10^{3} \mathrm{CFU} / \mathrm{ml}$. Dissolved oxygen (DO) was improved that elevated from $1.06 \pm 0.04$ to $5.09 \pm 0.03$ $\mathrm{mg} / \mathrm{L}$. However, chemical oxygen demand (COD) and biological oxygen demand (BOD) were increased from $520.5 \pm 0.71$ to $865.0 \pm 2.12 \mathrm{mg} / \mathrm{L}$ and from $120.5 \pm 2.12$ to $270.5 \pm 2.12 \mathrm{mg} / \mathrm{L}$ respectively. Nevertheless, there is no significant alteration of $\mathrm{pH}$, conductivity, salinity and total dissolved solid (TDS) after treatment. The iron (Fe) was fully removed while copper (Cu) and cadmium (Cd) were successfully removed up to $98 \%$. The reduction of lead $(\mathrm{Pb})$ also achieved $82.17 \%$. Also, (MOCR) can be stored for long time up to 6 months without affecting the biological properties of MO.
\end{abstract}

\section{Keywords}

Moringa oleifera, Waste Water Treatment, Dissolved Oxygen, Turbidity, Heavy Metals, Antibacterial

\footnotetext{
${ }^{*}$ Corresponding author.
} 


\section{Introduction}

Waste water is the by-product from municipal, agricultural and industrial activity [1]. The conditions of the waste water without treatment will be deleterious to the organism in the river and human health [2] [3]. In the era of globalization, many water treatment processes have been invented but most of them require higher expenditure [4] [5]. This is because water treatment plants are very complex and require many stages to purify the waste water. The more complex water treatment plant means the higher the expenditure [3]-[6].

A conventional method to treat the waste water is using chemical coagulant such as aluminium sulphate and iron salts [7] [8]. It is used as a coagulant to sediment down the particles from waste water. Nevertheless, chemical coagulants have many drawbacks when applied in water treatment [4] [8] [9]. Therefore, finding natural alternatives is of great importance. Thus, early studies have found that one of these alternatives for water treatment is Moringa oleifera (MO) [10] [11]. It was a traditional method for waste water treatment by using MO which possesses the same function with the chemical coagulant such as aluminium sulphate.

MO is the most studied of the 14 species that belong to genus Moringaceae and the scientific name of this species is MO [2] [11]. Leaves and seeds of MO are most widely used in water treatment [2] [12]. There is no significant side effect using MO in water treatment because it is reported as non-toxic and biodegradable material [2] [13].

The natural coagulant derived from MO seed is the by-product of oil extraction process. MOCR can be used directly in waste water treatment without further preparation [14]. Many laboratory studies have proven that persuasive coagulant properties are found in MO seed [6] [12] [15]-[17]. MOCR is removing turbidity from water by pulling together floating particles, which include dirt, solids particles, and even some bacteria and fungi [4] [12] [18]. MO seed possesses antibacterial properties [19], coagulant properties to flocculate particles [6] and acts as biosorbent for heavy metal removal [16] [20] [21].

This study aims to investigate the performance of MOCR on different water parameters such as: BOD, COD, DO, TDS, $\mathrm{pH}$, salinity and conductivity, using different concentrations of MOCR applied to waste water. In addition, the study the turbidity removal, heavy metal removal and reduction of bacterial consortium in wastewater and investigate the effect of MOCR storage time on treated water properties.

\section{Materials and Methods}

\subsection{Experimental Site}

The waste water samples were collected from two target sites which are Gebeng River (GR) and waste water (WW). Gebeng River (GR) is located at main industrial area in Kuantan, Pahang State, Malaysia, it is important to study the water quality status of this river because effluents from industrial area of Gebeng are discharged into it which deteriorating the water quality. The type of waste water (WW) used in this study is leachate and collected from landfill which is located along Jabor-Kerangau Road, District of Kuantan, Pahang State, Malaysia.

\subsection{Mo Seeds Preparation}

\subsubsection{Oil Extraction}

The soxhlet extraction method was used to extract the oil from MO [22]. About $10 \mathrm{~g}$ of MO seed powder were put into an extraction thimble. A $170 \mathrm{ml}$ of hexane solvent was poured into a round bottom flask. After set up the soxhlet apparatus, the hexane solvent was heated for $45 \mathrm{~min}$ and the oil was extracted. After extraction, MOCR was collected from the thimble and dried in an oven at $50^{\circ} \mathrm{C}$ for overnight. Once the oil was fully removed from the MO seed, the seed cake residue could be used in water treatment. Two samples of MOCR were used for water treatment, one of freshly prepared cake residue is called Hexane Freshly Prepared (HFP), and the second sample was stored for six months to study the effect of storage time on the performance of the cake residue in water treatment and called Hexane Long Storage (HLS). The oil was extracted from the seeds because the presence of oil in the MO seed would affect the coagulation activity and heavy metal removal [23]. The higher the oil content in MO seed, the lower the performance of the MOCR in water treatment process.

\subsubsection{Stock Solution Preparation}

The stock solution was prepared by adding the distilled water to MOCR in different concentrations to form a 
paste which possesses the coagulation activity. Different concentrations were prepared in distilled water (mg/5ml) by dissolving 50, 100 and $150 \mathrm{mg}$ of the seed powder to obtain 10,000, 20,000 and 30,000 mg/L with percentage of $1 \%, 2 \%$ and $3 \%$, respectively [19].

\subsection{Waste Water Treatment}

A waste water treatment was performed by using a PB-700 6 Paddle Jar Test apparatus. Six beakers were labelled. About $500 \mathrm{ml}$ water sample was prepared into each beaker and placed into a Jar Test apparatus. Different concentrations of stock solution was added into each beaker and operated with initial speed of $150 \mathrm{rpm}$ for 2 min. Then, the speed was reduced to $50 \mathrm{rpm}$ and continued for $25 \mathrm{~min}$. Then water samples were left for setting for 1 hour [11] [19]. After 1 hour, clear water sample was collected into the conical flask and stored at $4^{\circ} \mathrm{C}$ for further analysis.

\subsubsection{Heavy Metal Removal Measurement}

The heavy metal removal test was done by using a PerkinElmer AAnalyst ${ }^{\mathrm{TM}} 800$ High-Performance Atomic Absorption Spectrometer (AAS). A series of calibration solution such as copper, iron, lead and cadmium were prepared from standard stock solution $(1000 \mathrm{mg} / \mathrm{L})$. Each of the elements was prepared with 5 different concentrations of 0.5 to $7 \mathrm{ppm}$ [17]. Each water sample was diluted ten-folds before analysing by AAS.

\subsubsection{Turbidity Measurement}

Turbidity of water was measured by using a 2100P (HACH) turbidimeter. Turbidity of water sample was measured before and after treatment to monitor the performance of MOCR [24].

\subsubsection{Chemical Oxygen Demand (COD) Measurement}

A DR2800 spectrophotometer was used to measure the COD in water samples. About $2 \mathrm{ml}$ of the water sample before and after treatment were pipetted into COD reagent vials and inserted into a COD reactor. The sample was heated at $150^{\circ} \mathrm{C}$ for 2 hours with a strong oxidizing agent (potassium dichromate solution) to oxidize organic matter chemically [25].

\subsubsection{Biochemical Oxygen Demand (BOD) Measurement}

BOD measurements were done by using a dissolved oxygen (DO) meter. About $1 \mathrm{~L}$ of diluted water sample was prepared by adding $1 \mathrm{ml}$ of phosphate buffer, magnesium sulfate, calcium chloride and ferric chloride solution into $996 \mathrm{ml}$ distilled water. About $10 \mathrm{ml}$ of water sample prior to and after treatment was transferred into each BOD bottle. Then, $300 \mathrm{ml}$ of diluted water was added into the BOD bottle. Besides that, the control was prepared from $300 \mathrm{ml}$ diluted water in BOD bottle. The DO was measured for all samples using DO meter. After that, the diluted water was added to the flared mouth of the bottle and covered with aluminium foil to prevent evaporation of the solution. All bottles were put into the BOD incubator for 5 days at $20^{\circ} \mathrm{C}$. The DO value was measured after 5 days [26]. The BOD was much higher than the limited solubility of oxygen in water; hence, it was necessary to make a series of dilutions.

\subsubsection{Conductivity, pH, Total Dissolved Solid (TDS), Dissolved Oxygen (DO) and Salinity Measurement}

The conductivity, pH, TDS, DO and salinity can be examined by using a multifunction PCD650 waterproof portable meter (CyberScan Waterproof Portable pH/ORP/Conductivity Meter Eutech Instruments). The measurements before the treatment of the waste sample were carried out directly in situ, and measurements after treatment with MOCR were taken in the laboratory.

\subsubsection{Antibacterial Assay for Water Sample}

The antibacterial assay was performed to investigate the microbiological quality of water sample. Pour plate method was used to examine the reduction of bacteria from water sample [2]. This test were conducted prior to treatment and after the water treatment by different concentration of MOCR. A series of dilutions up to $10^{-6}$ of the water sample were made before and after treatment using plating onto the nutrient agar (NA) plate [19]. About $0.1 \mathrm{ml}$ aliquot of each dilution 1 to 6 test tubes were transferred onto the NA surface. Then, evenly spread onto the agar surface by using L-shape glass rod. The NA plates were incubated at $37^{\circ} \mathrm{C}$ overnight. The number 
of colonies grown on the plate was counted. The number of colonies before and after treatment was compared.

\section{Results and Discussion}

\subsection{Oil Extraction}

The results significantly proved that the hexane is suitable for MO seed oil extraction based on the high oil yield which is $34.77 \%$. The result obtained was strongly agreed with [18] [23].

\subsection{Water Analysis Parameters}

\subsubsection{River Water}

Many tests have been carried out for the GR water samples before and after treatment, using two types of MOCR (HFP and HLS). The results are shown in Table 1.

Most researchers had figured out that MOCR have the ability to remove 95\% - 99\% turbidity from waste water [7] [8] [11]. Previous studies also indicated that MOCR used in waste water treatment will increase the COD due to presence of organic matter [14].

Data recorded in Table 1, revealed that the pH of the GR was not significantly changed after treatment with MOCR in both samples of cake residue from (HFP) and (HLS). The $\mathrm{pH}$ was in range of 6.5 - 8.5 (National Water Quality Standard for Malaysia). This proved that (MOCR) is not affecting $\mathrm{pH}$ in water samples which showed agreement with [6] [8] [14] [19]. The storage duration does not affect the $\mathrm{pH}$ as well.

Moreover, the conductivity was increased after treatment within $50 \mu \mathrm{S} / \mathrm{cm}$. It was elevated from $347 \pm 0.00$ to $392 \pm 0.00 \mu \mathrm{S} / \mathrm{cm}$. TDS also increased after treatment from $307 \pm 0.00$ to $425 \pm 0.00 \mathrm{ppm}$. The increasing of TDS was not agreed with [27] which stated that the TDS was reduced after the treatment with MOCR. This was due to the different pre-treatment steps used in the experiment. But, according to current result, the conductivity and TDS were in agreement with [8]. For salinity, it was increased from $353 \pm 0.00$ to $418 \pm 0.00 \mathrm{ppm}$. The results were similar with the investigation carried out by [14]. Concentration of MOCR will affect the result of conductivity as indicated by [19] that conductivity increases as more MOCR is added to water. Besides that, conductivity, salinity and TDS using HFP were higher than that when HLS is applied. Thus, storage duration didn't affect salinity, TDS and conductivity and they followed the same trend since they are related to each other [8] [14].

The COD of GR after treatment was lower than that before treatment which was $132.0 \pm 2.83$ and dropped to $88.5 \pm 0.71 \mathrm{mg} / \mathrm{L}$ when $1 \%$ MOCR from HFP was used and $93.3 \pm 0.00 \mathrm{mg} / \mathrm{L}$ when $1 \%$ MOCR from HLS was applied (Table 1), the results agreed with [10]. However, it was in contrast with [26] results which showed a great reduction of COD after treatment, this might be due to the additional treatment steps of MOCR used. The

Table 1. GR water samples parameters before and after treatment using MOCR.

\begin{tabular}{|c|c|c|c|c|c|c|c|}
\hline \multirow{3}{*}{ Parameters } & \multirow{3}{*}{$\begin{array}{c}\text { Before } \\
\text { treatment }\end{array}$} & \multicolumn{3}{|c|}{$\mathrm{HLS}^{1}$} & \multicolumn{3}{|c|}{$\mathrm{HFP}^{2}$} \\
\hline & & \multicolumn{3}{|c|}{ MOCR concentration, $\%$ (mean \pm SD) } & \multicolumn{3}{|c|}{ MOCR concentration, \% (mean \pm SD) } \\
\hline & & 1.0 & 2.0 & 3.0 & 1.0 & 2.0 & 3.0 \\
\hline $\mathrm{pH}$ & $8.06 \pm 0.03$ & $8.02 \pm 0.02$ & $8.08 \pm 0.01$ & $8.11 \pm 0.01$ & $8.06 \pm 0.17$ & $8.14 \pm 0.06$ & $8.10 \pm 0.01$ \\
\hline $\mathrm{BOD}(\mathrm{mg} / \mathrm{l})$ & $100.10 \pm 0.00$ & $46.05 \pm 1.06$ & $57.60 \pm 2.97$ & $66.90 \pm 0.85$ & $41.40 \pm 0.42$ & $53.55 \pm 3.61$ & $66.15 \pm 0.64$ \\
\hline COD (mg/L) & $132.0 \pm 2.83$ & $93.3 \pm 0.00$ & $109.0 \pm 1.41$ & $141.0 \pm 2.83$ & $88.5 \pm 0.71$ & $100.5 \pm 0.71$ & $132.0 \pm 1.41$ \\
\hline Conductivity $(\mu \mathrm{S} / \mathrm{cm})$ & $347 \pm 0.00$ & $358.5 \pm 0.71$ & $380 \pm 0.00$ & $390 \pm 1.41$ & $361 \pm 1.41$ & $383 \pm 0.00$ & $392 \pm 0.00$ \\
\hline Salinity (ppm) & $353 \pm 0.00$ & $375 \pm 2.83$ & $402 \pm 0.00$ & $415 \pm 1.41$ & $378.5 \pm 2.12$ & $406 \pm 0.00$ & $418 \pm 0.00$ \\
\hline TDS (ppm) & $307 \pm 0.00$ & $334 \pm 5.66$ & $357 \pm 0.00$ & $410 \pm 1.41$ & $339 \pm 0.00$ & $364 \pm 4.24$ & $425 \pm 0.00$ \\
\hline DO (mg/L) & $2.58 \pm 0.01$ & $3.44 \pm 0.03$ & $4.57 \pm 0.04$ & $5.02 \pm 0.02$ & $4.07 \pm 0.03$ & $5.50 \pm 0.01$ & $5.94 \pm 0.03$ \\
\hline Turbidity (NTU) & $67.25 \pm 0.07$ & $9.60 \pm 0.14$ & $7.72 \pm 0.01$ & $4.93 \pm 0.02$ & $8.43 \pm 0.04$ & $5.93 \pm 0.04$ & $4.55 \pm 0.02$ \\
\hline
\end{tabular}

${ }^{1}$ Hexane long storage batch; ${ }^{2}$ Hexane freshly prepared batch. 
COD after treatment was lower than initial COD accept the use of \% MOCR were the COD was higher than initial COD. MOCR is non-toxic for water purification [14], and it is considered as encouraging results and safe to environment and aquatic organism. The increasing of COD depends on the MOCR dosage used and MOCR concentration was directly proportional to the COD. The best concentration for the COD reduction was $1 \%$ of MOCR since it showed the highest reduction in COD value. Besides that, the storage duration was not significant, and the HFP was better in removing COD due to the fresh preparation of the seed cake.

Furthermore, BOD after treatment was dramatically reduced and the results agreed with [28] where $40 \%$ of BOD can be reduced after the MOCR treatment especially at 3\% (150 mg/L of MOCR stock solution). This means that the MOCR concentration will affect the BOD after treatment. The BOD was reduced from $100.10 \pm$ 0.00 to $41.40 \pm 0.42 \mathrm{mg} / \mathrm{L}$ (after treatment with 1\% HFP). This result was similar with the research of [26] [28]. However, [20] had reported that the BOD was not significantly increased or decreased after the treatment. The results of BOD using HFP were slightly better than results when HLF was applied to water samples. Meanwhile, the concentration of the MOCR was affecting the BOD, higher concentration of MOCR revealed higher BOD value, and storage duration does not influence the MOCR performance.

Based on Table 1, DO was dramatically improved after treatment, $2.58 \pm 0.01$ improved to $5.94 \pm 0.03 \mathrm{mg} / \mathrm{L}$ ( $3 \%$ MOCR of HFP) and $5.02 \pm 0.02 \mathrm{mg} / \mathrm{L}$ (3\% MOCR of HLS). There are two factors affecting the DO results which are dosage used and storage duration of the MOCR. For the comparison of storage duration, HFP showed better results of DO than the results using HLS, the MOCR concentration is directly proportional to the DO value. Hence, it was excellent to improve the DO by using MOCR, the DO reading of HFP (3\%) and HLS (3\%) were in the range of 5 - $7 \mathrm{mg} / \mathrm{L}$ which considered as first class water quality according to National Water Quality Standards for Malaysia.

In addition, MOCR also plays a vital role to reduce the turbidity. The initial turbidity of GR was in the low range $67.25 \pm 0.07$ NTU, MOCR successfully removed 85\% - 93\% turbidity from the GR (Table 1 ). This result was totally agreed with most of the previous investigations [4] [6] [8] [11] [14] [17] [29] [30]. According to the Table 1, 3\% of MOCR have removed more than $90 \%$ of turbidity which was reduced to $4.55 \pm 0.02$ NTU and $4.93 \pm 0.02$ NTU using HFP and HLS, respectively, followed by $2 \%$ of MOCR. Hence, the higher concentration of MOCR means the better coagulation properties. According to National Water Quality Standard Malaysia and [31], the first class water and drinking water quality should have turbidity $<5.0$ NTU. This proved that the storage period of MOCR will not affect the turbidity removal in water treatment process.

\subsubsection{Waste Water}

Many tests have been carried out for the water before and after treatment for WW, using two types of MOCR (HFP and HLS). The results are shown in Table 2.

Data recorded in Table 2 exhibited that the $\mathrm{pH}$ of the WW was not significantly changed after treatment; this

Table 2. WW water samples parameters before and after treatment using MOCR.

\begin{tabular}{|c|c|c|c|c|c|c|c|}
\hline \multirow{3}{*}{ Parameters } & \multirow{3}{*}{$\begin{array}{l}\text { Before } \\
\text { treatment }\end{array}$} & \multicolumn{3}{|c|}{ HLS $^{1}$} & \multicolumn{3}{|c|}{$\mathrm{HFP}^{2}$} \\
\hline & & \multicolumn{3}{|c|}{ MOCR concentration, $\%$ (mean \pm SD) } & \multicolumn{3}{|c|}{ MOCR concentration, $\%$ (mean \pm SD) } \\
\hline & & 1.0 & 2.0 & 3.0 & 1.0 & 2.0 & 3.0 \\
\hline $\mathrm{pH}$ & $7.15 \pm 0.01$ & $6.94 \pm 0.01$ & $6.89 \pm 0.00$ & $7.02 \pm 0.03$ & $6.99 \pm 0.03$ & $6.90 \pm 0.03$ & $7.08 \pm 0.01$ \\
\hline BOD (mg/l) & $120.5 \pm 2.12$ & $171.5 \pm 2.12$ & $227.0 \pm 1.41$ & $270.5 \pm 2.12$ & $179.5 \pm 0.71$ & $205.5 \pm 0.71$ & $250.5 \pm 4.94$ \\
\hline COD (mg/L) & $520.5 \pm 0.71$ & $516.0 \pm 0.00$ & $754.5 \pm 7.79$ & $865.0 \pm 2.83$ & $510.0 \pm 5.66$ & $658.5 \pm 4.95$ & $739.5 \pm 2.12$ \\
\hline Conductivity $(\mu \mathrm{S} / \mathrm{cm})$ & $402 \pm 1.41$ & $421 \pm 0.14$ & $470 \pm 2.83$ & $446 \pm 2.83$ & $428 \pm 0.00$ & $478 \pm 0.00$ & $451.3 \pm 1.84$ \\
\hline Salinity (ppm) & $421 \pm 0.85$ & $431 \pm 2.55$ & $471.2 \pm 0.57$ & $460.1 \pm 0.14$ & $436 \pm 0.00$ & $478 \pm 2.83$ & $443.7 \pm 3.25$ \\
\hline TDS (ppm) & $412 \pm 0.00$ & $399 \pm 0.00$ & $438 \pm 1.41$ & $430.5 \pm 0.71$ & $403 \pm 0.00$ & $458 \pm 1.41$ & $411.8 \pm 0.57$ \\
\hline $\mathrm{DO}(\mathrm{mg} / \mathrm{L})$ & $1.06 \pm 0.04$ & $3.00 \pm 0.02$ & $3.93 \pm 0.04$ & $4.60 \pm 0.02$ & $3.27 \pm 0.08$ & $4.44 \pm 0.08$ & $5.09 \pm 0.03$ \\
\hline Turbidity (NTU) & $148.3 \pm 0.42$ & $6.65 \pm 0.07$ & $5.08 \pm 0.03$ & $4.79 \pm 0.02$ & $6.06 \pm 0.04$ & $5.16 \pm 0.05$ & $4.19 \pm 0.03$ \\
\hline
\end{tabular}

${ }^{1}$ Hexane long storage batch; ${ }^{2}$ Hexane freshly prepared batch. 
was due to the use of natural material for water treatment [8]. The MOCR concentration and storage duration did not have any effect on $\mathrm{pH}$ of treated water, the results agreed with investigation by [14] [24] [26]. Thus, there was no addition step to adjust the $\mathrm{pH}$ value after the treatment. Hence, MOCR was suggested for water treatment industry [2].

There was no alteration on conductivity, TDS and salinity result after the treatment. Result from Table 2 was totally agreed with [8]. The conductivity, TDS and salinity of WW before treatment were $402 \pm 1.41 \mu \mathrm{S} / \mathrm{cm}, 412$ $\pm 0.00 \mathrm{ppm}$, and $421 \pm 0.85 \mathrm{ppm}$, respectively. Based on Table 2, these parameters using $2 \%$ MOCR was slightly higher than the results when other concentrations were applied. It was reported by [24] that when the concentration of MOCR increase the water conductivity will be decreased. However, the previous reports from [14] indicated that the MO coagulant will not influence the conductivity and TDS. Thus, the results of WW were similar with the investigation from [14]. Moreover, storage duration of MOCR did not influence these parameters in water quality.

In addition, the COD result of GR was totally different from WW, the COD of WW was dramatically increased after treatment. By using HLS the COD was increased more than the case when HFP was applied, which was increased from $520.5 \pm 0.71$ to $865 \pm 2.83 \mathrm{mg} / \mathrm{L}$. While by using HFP the COD was increased from $520.5 \pm$ 0.71 to $739.5 \pm 2.12 \mathrm{mg} / \mathrm{L}$. This means the storage period will deteriorate the function of MOCR and the initial water quality is affecting the performance of MOCR since WW have more initial COD than GR as shown in Table 1 and Table 2 . This is because treatment of the water sample with natural material usually will show this effect [32], and there is no way to prevent the increasing of COD after treatment with natural source. In short, dosage of MOCR was the major factor that caused the increasing of COD after treatment [14]. BOD also exhibited the same trend of COD, the BOD after treatment was increased with the increase of MOCR dosage (Table 2), and the results are not acceptable for the drinking water standard [31]. After treatment, the BOD increased especially by using HLS $(270.5 \pm 2.12 \mathrm{mg} / \mathrm{L})$, then followed by HFP $(250.5 \pm 4.94 \mathrm{mg} / \mathrm{L})$. But, this result was in contrast with [20] [28]. Besides that, [26] also presented the reduction of BOD after treatment with MO, and this was due to the addition treatment steps with chemical coagulants used in the experiment.

On the other hand, DO value significantly increased after the treatment, and the effect of MOCR in WW was similar with GR. DO was improved from $1.06 \pm 0.04$ to $4.60 \pm 0.02 \mathrm{mg} / \mathrm{L}$ (using 3\% MOCR of HLS) and $5.09 \pm$ $0.03 \mathrm{mg} / \mathrm{L}$ (applying 3\% MOCR of HFP). DO results by using HFP are better than HLS performance; this proved that storage duration will affect the MOCR in water treatment. Besides that, the MOCR concentration is directly proportional to the DO value; hence, it was strongly suggested using MOCR to improve the DO value. The improvement of DO in water sample after treatment is due to oil extraction from MO seeds.

The turbidity of WW before treatment is considered as medium level with turbidity of $148.3 \pm 0.42$ NTU. MOCR successfully removed the turbidity from WW up to 97\% (by using 3\% MOCR of HFP), and this reading was proven by previous research work [4] [8] [26] [29]. According to Table 2, 1\% MOCR of HLS has reduced turbidity up to $6.65 \pm 0.07 \mathrm{NTU}$, followed by the $2 \%$ and $3 \%$ which are $5.08 \pm 0.03$ and $4.79 \pm 0.02 \mathrm{NTU}$, respectively. Although the residual turbidity using HLS was similar to that when HFP is used, but, HFP showed the best coagulation effect in WW. MOCR with 1\% MOCR of HFP has reduced the turbidity to $6.06 \pm 0.04$ NTU, followed by $2 \%$ and $3 \%$ of HFP which were $5.16 \pm 0.05$ and $4.19 \pm 0.03$ NTU, respectively. The turbidity removal result after the treatment was accepted by the [31] guideline for drinking water with $<5$ NTU.

\subsection{Heavy Metals Removal Results}

\subsubsection{Heavy Metals Removal from GR}

Figure 1 shows heavy metal adsorption using MOCR with GR water samples. The heavy metal binds with polyelectrolyte from MOCR to form complexes [12], and this polyelectrolyte released after oil extraction since it is not soluble in lipid [18] [20].

The heavy metals of $\mathrm{Cu}, \mathrm{Cd}, \mathrm{Fe}$ and $\mathrm{Pb}$ were high in the GR water samples. After ten-fold dilution, the concentration of these metals still more than $1 \mathrm{mg} / \mathrm{L}$. This indicated that GR water contains a high concentration of heavy metals in the stream. MOCR can act as natural adsorbent to remove the heavy metals from water sample [4] [21]. Two factors were studied to investigate the effect of MOCR activity in heavy metal removal namely dosage of MOCR, and storage duration.

HFP showed that $\mathrm{Cu}$ can be removed $100 \%$ when compared with the HLS which indicated $0.012 \mathrm{mg} / \mathrm{L}$ of $\mathrm{Cu}$ remains after treatment with $1 \%$ MOCR, followed by the $2 \%$ and $3 \%$ which showed $\mathrm{Cu}$ residual of 0.007 and 


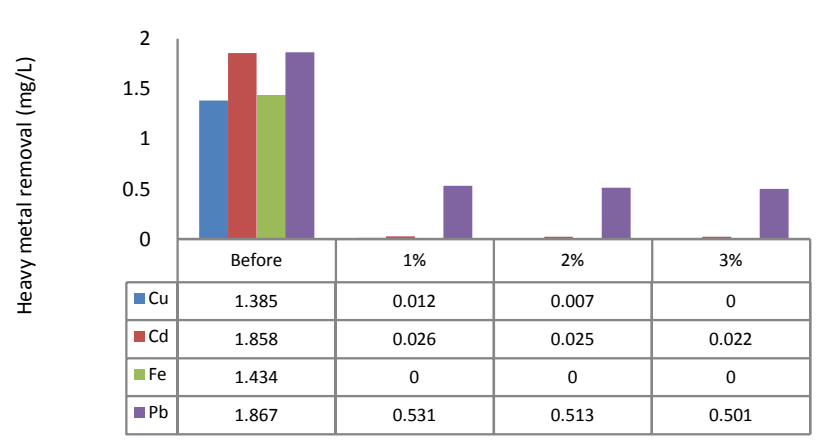

(a)

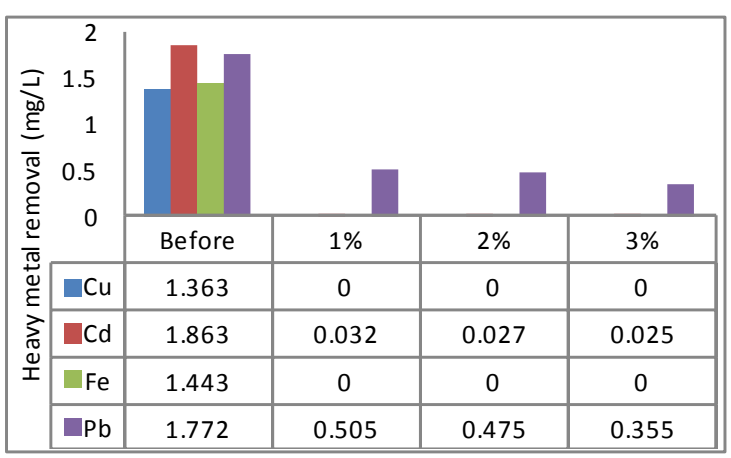

(b)

Figure 1. Heavy metal removal from GR using MOCR. (a) hexane long storage batch (HLS); (b) hexane freshly prepared batch (HFP).

$0.00 \mathrm{mg} / \mathrm{L}$, respectively. This means that, the higher MOCR dosage, gives better reduction of $\mathrm{Cu}$, the same trend is followed using HLS with fully reduction of Cu using 3\% MOCR. According to [30], MOCR was good to remove $\mathrm{Cu}$ up to $90 \%$, the increasing of MOCR concentration revealed better reduction; similarly, [17] had reported that MOCR has ability to show adsorption of $\mathrm{Cu}$. The concentration of $\mathrm{Cu}$ after treatment was in range of the standard drinking water from [31].

On the other hand, Cd showed significant decreasing after the treatment with natural absorbent [18]. Obviously, more than $98 \%$ of Cd was removed at the end of the treatment, and as shown in Figure 1, it was better than that reported by [17] which only exhibited $60 \%$ of Cd removal by MO seed. Cd removal was different with other heavy metal because the storage periods did not affect the removal action. However, higher concentration of MOCR revealed better removal of Cd, in contrast with [20] who reported that only $48 \%$ of Cd was removed from the treated water, this might be due to different method used for pre-treatment of the MO seed. [20] have used the seed powder directly without oil extraction. Cd removal is acceptable for National Water Quality Standard for Malaysia when treated with MOCR, although it was not fully removed from water samples.

In addition, Fe was not detected after the treatment. The initial amount of Fe was above $1.40 \mathrm{mg} / \mathrm{L}$ and fully removed by MOCR. This result was totally agreed with [8] study, while [20] had reported that a reduction of Fe by using MOCR was up to $92 \%$ if compared to other heavy metals. There is no difference between the concentrations of MOCR used for iron removal from water sample because there is no Fe was detected after treatment. In addition, Fe was fully removed by HLS, the level of Fe was achieved the water standards since concentration of Fe in water should be less than $0.30 \mathrm{mg} / \mathrm{L}$ (National Water Quality Standard from Malaysia). Hence, the long storage period did not deteriorate the MOCR for heavy metal removal.

Figure 1 shows the reduction of $\mathrm{Pb}$ was up to $80 \%$ using 3\% HFP (residual $\mathrm{Pb}$ was $0.355 \mathrm{mg} / \mathrm{L}$ ), while $\mathrm{Pb}$ in water standard should be less than $0.05 \mathrm{mg} / \mathrm{L}$. Although the MOCR showed some reductions of $\mathrm{Pb}$ in treated water, but the result was not good enough to meet the drinking water standard [31]. In this study, the removing of $\mathrm{Pb}$ was within the range of previous research [20] [30] which indicated that $\mathrm{Pb}$ can be removed within $80 \%$ $89 \%$ by using MO seed if compared to other natural source such as beans and peanuts.

\subsubsection{Heavy Metals Removal from Waste Water (WW)}

The concentrations of heavy metals in WW were higher than GR, and as shown in Figure 2, heavy metal removal efficiency of MOCR in WW was similar to GR. Removal of Pb was up to $82 \%$ in WW which comes in agreement with [30], which indicated that $80 \%$ of $\mathrm{Pb}$ can be removed by using MOCR. The optimum reduction for $\mathrm{Pb}$ from WW was HFP, and HLS also showed reduction of $\mathrm{Pb}$ after treatment, the higher MOCR concentration, the higher removal of $\mathrm{Pb}$ from WW.

As shown in Figure 2, HFP has removed $99 \%$ of $\mathrm{Cu}$, and HLS removed $100 \%$, and this result was better than [30] results of $\mathrm{Cu}$ where MOCR was able to remove $\mathrm{Cu}$ up to 90\%. The higher dosage of MOCR used the better $\mathrm{Cu}$ removal, and $\mathrm{Cu}$ was not detected after treatment with $2 \%$ and $3 \%$ of HFP.

Furthermore, Fe was fully removed by MOCR, and this result is in agreement with [4] [8]. Based on an investigation from [20], removal of Fe by MOCR reached up to 92\%.

Other than that, Cd was the other heavy metal that showed significant decreasing after the treatment. The ini- 


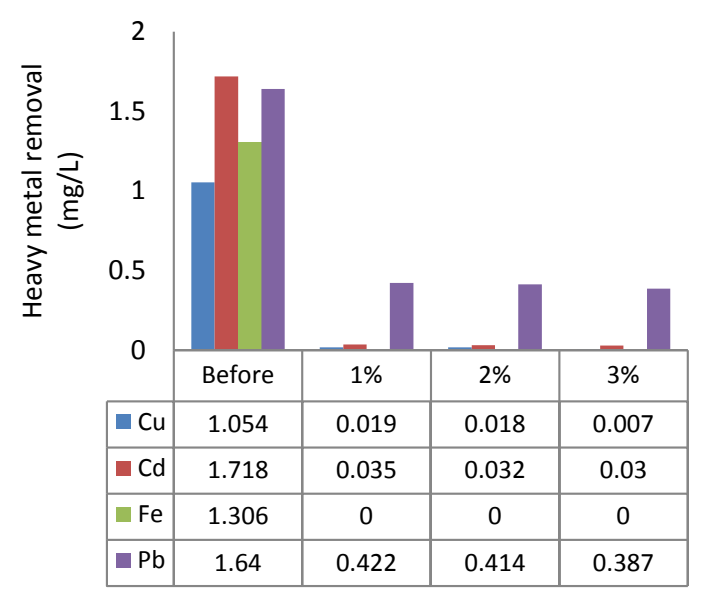

(a)

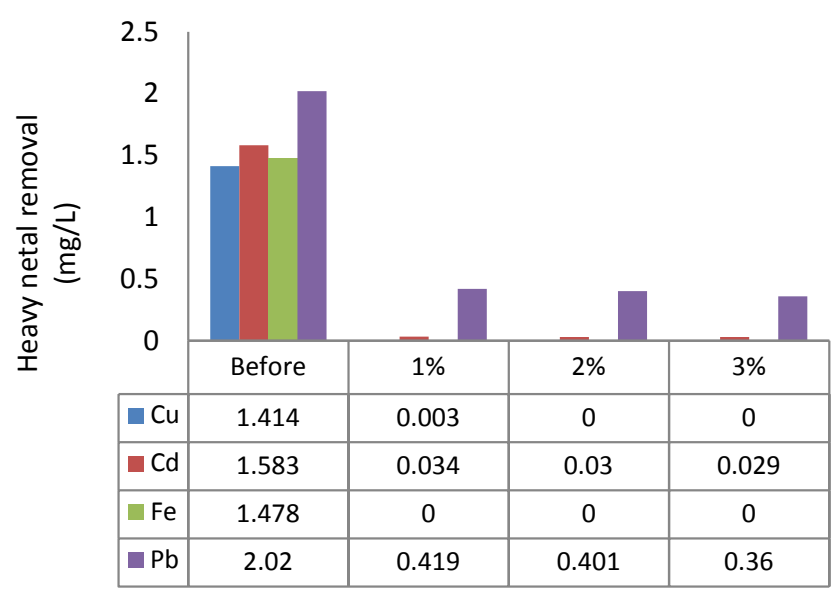

(b)

Figure 2. Heavy metal removal from WW using MOCR. (a) hexane long storage batch (HLS); (b) hexane freshly prepared batch (HFP).

tial level of Cd was more than $1.58 \mathrm{mg} / \mathrm{L}$ when HFP and $1.718 \mathrm{mg} / \mathrm{L}$ when HLS. HFP has reduced the Cd to $0.034 \mathrm{mg} / \mathrm{L}$ by adding 1\% MOCR, $0.03 \mathrm{mg} / \mathrm{L}$ using 2\% MOCR, and $0.029 \mathrm{mg} / \mathrm{L}$ treated with 3\% MOCR. HLS has reduced Cd up to $0.035 \mathrm{mg} / \mathrm{L}$ using 1\% MOCR, $0.032 \mathrm{mg} / \mathrm{L}$ by adding $2 \%$ MOCR and $0.003 \mathrm{mg} / \mathrm{L}$ using $3 \%$ MOCR. Cd was removed up to $98 \%$. Storage period did not affect too much in the removal of Cd, nevertheless, the result of Cd removal was in contrast with [20] since the latter results showed $48 \%$ of Cd was removed which it might be due to the absence of pre-treatment step for MO seeds.

In this experiment, two factors affecting the efficiency of MOCR in heavy metal removal was examined. MOCR dose played the major role in the heavy metal removal; the higher MOCR dosage gives better reduction of heavy metal. According to Figure 1, and Figure 2, 1\% of MOCR was enough to remove the heavy metal. Next, the storage duration was also examined, where the long storage batch (6 months) was compared with the freshly prepared batch. However, the long storage duration of MOCR was not affecting in heavy metal removal. Therefore, MOCR can be stored for long time up to 6 months without affecting the performance in water treatment.

\subsection{Antibacterial Assay}

MOCR was used to investigate the effect on bacteria presented in water. Table 3 shows the different bacteria count using MOCR for GR and WW water samples.

Before treatment with MOCR, there is high concentration of the bacteria present in the water sample for GR and WW. Both were unsafe for human consumption due to high amount of bacteria. Table 3 shows the initial concentration of bacteria in the GR and WW were $1.70 \times 10^{5}$ and $1.06 \times 10^{6} \mathrm{CFU} / \mathrm{ml}$, respectively. Higher concentration of bacterial presence in the water sample might link to disease outbreak and it is harmful to environment. However, MOCR did not fully inhibit bacteria from water sample [2] [19], but, it does help prevent the growth of microorganism. According to [8], MOCR showed better antibacterial properties than chemical coagulant.

Based on Table 3, MOCR was successfully reduced the bacterial growth in water samples after treatment. The bacterial count in WW after treatment was $7.90 \times 10^{3} \mathrm{CFU} / \mathrm{ml}$ and almost same to the bacterial count after treatment of GR $8.00 \times 10^{3} \mathrm{CFU} / \mathrm{ml}$. The storage duration is one of the factors affecting the antimicrobial effect of MOCR, HFP was slightly better than HLS in the removal of bacteria. However, the long storage duration do not deteriorate the MOCR since it showed the reduction of bacterial after the treatment as well.

It was reported by [19] that the antimicrobial activity is dependent on the concentration of MOCR, and the higher concentration used revealed better antimicrobial effect [8] [32]. The previous reports had emphasised that MOCR possess the antimicrobial function and reduce the number of bacterial colonies as reported by [13] [24] [33] [34] that active component from MO seed possess antibacterial properties and antipyretic. 
Table 3. Bacteria count in GR \& WW using MOCR.

\begin{tabular}{ccccc}
\hline \multirow{2}{*}{ MOCR concentration (\%) } & \multicolumn{2}{c}{$\begin{array}{c}\text { Bacterial count from GR using } \\
\text { different solvents (CFU/ml) }\end{array}$} & HFP $^{2}$ & \multicolumn{2}{c}{$\begin{array}{c}\text { Bacterial count from WW using } \\
\text { different solvents (CFU/ml) }\end{array}$} \\
\hline Hefs & HLS $^{1}$ & $1.06 \times 10^{6}$ & $1.06 \times 10^{6}$ \\
1.0 & $1.70 \times \times 10^{5}$ & $1.70 \times 10^{5}$ & $8.70 \times 10^{4}$ & $2.10 \times 10^{4}$ \\
2.0 & $8.40 \times 10^{4}$ & $10.50 \times 10^{3}$ & $7.30 \times 10^{4}$ & $9.85 \times 10^{3}$ \\
3.0 & $8.10 \times 10^{4}$ & $9.80 \times 10^{3}$ & $6.11 \times 10^{4}$ & $7.90 \times 10^{3}$
\end{tabular}

${ }^{1}$ Hexane long storage batch; ${ }^{2}$ Hexane freshly prepared batch.

\section{Conclusion}

In general, MOCR was a good coagulant for water treatment. The extraction oil yield from MO seed was 34.77\% by using hexane. It successfully reduced and prevented bacterial growth for WW and GR water samples. The turbidity was removed up to $97 \%$ after treatment, DO was significantly improved and no changing of pH but slightly alteration of certain water parameters such as conductivity, salinity and TDS as well. Increasing of COD and BOD cannot be avoided due to presence of organic matter in the MOCR. However, this did not bring the toxic effect and was not harmful to human health. Besides that, MOCR successfully removed the heavy metal from waste water, Fe was fully removed while $\mathrm{Cu}$ and $\mathrm{Cd}$ were successfully removed up to 98\%, and the reduction of $\mathrm{Pb}$ was up to $82.17 \%$. Overall, $1 \%$ of (MOCR) was enough to remove heavy metals from GR and WW.

\section{Acknowledgements}

The author would like to thank Research \& Innovation Department/Universiti Malaysia Pahang/Malaysia, for financial support to publish this paper under grant \#: RDU 140304. The author would like to thank the Faculty of Industrial Sciences and Technology/Universiti Malaysia Pahang/Malaysia for using their facilities to perform the experimental work.

\section{References}

[1] Ellis, T.G. (2004) Chemistry of Wastewater. Environment and Ecological Chemistry, 2.

[2] Arafat, M.G. and Mohamed, S.O. (2013) Preliminary Study on Efficacy of Leaves, Seeds and Bark Extracts of Moringa oleifera in Reducing Bacterial load in Water. International Journal of Advanced Research, 1, 124-130.

[3] Horne, J. (2013) Economic Approaches to Water Management in Australia. International Journal of Water Resources Development, 29, 526-543. http://dx.doi.org/10.1080/07900627.2012.712336

[4] Joshua, R. and Vasu, V. (2013) Characteristics of Stored Rain Water and Its Treatment Technology Using Moringa Seeds. International Journal of Life Science and Pharma Reviews, 2, 155-174.

[5] Johnstone, D.W.M. (2013) Regulation and Reality: Some Reflections on 50 Years of International Experience in Water and Wastewater. International Journal of Water Resources Development, 30, 345-354. http://dx.doi.org/10.1080/07900627.2013.842088

[6] Ghebremichel, K.A., Gunaratna, K.R., Henriksson, H., Brumer, H. and Dalhammar, G. (2005) A Simple Purification Activity Assay of the Coagulant Protein from Moringa oleifera Seed. Water Research, 39, 2338-2344. http://dx.doi.org/10.1016/j.watres.2005.04.012

[7] Gidde, M.R., Bhalerao, A.R. and Malusare, C.N. (2012) Comparative Study of Different Forms of Moringa oleifera Extracts for turbidity Removal. International Journal of Engineering Research and Development, 2, 14-21.

[8] Egbuikwem, P.N. and Sangodoyin, A.Y. (2013) Coagulation Efficacy of Moringa oleifera Seed Extract Compared to Alum for Removal of Turbidity and E. coli in Three Different Water Sources. European International Journal of Science and Technology, 2, 13-20.

[9] Madrona, G.S., Branco, I.G., Seolin, V.J., Filho, B.A.A., Fagundes-Klen, M.R. and Bergamasco, R. (2012) Evaluation of Extracts of Moringa oleifera Lam Seed Obtained with NACl and Their Effects on Water Treatment. Acta Scientiarum. Technology, 34, 289-293. http://dx.doi.org/10.4025/actascitechnol.v34i3.9605

[10] Bhuptawat, H., Folkard, G.K. and Chaudhari, S. (2007) Innovative Physico-Chemical Treatment of Wastewater Incorporating Moringa oleifera Seed Coagulant. Journal of Hazardous Materials, 142, 477-482. 
http://dx.doi.org/10.1016/j.jhazmat.2006.08.044

[11] Lea, M. (2010) Bioremediation of Turbid Surface Water Using Seed Extract from Moringa oleifera Lam. (Drumstick) Tree. Current Protocols in Microbiology, 16, 1G.2.1-1G.2.14. http://dx.doi.org/10.1002/9780471729259.mc01g02s16

[12] Mustapha, H.B. (2013) A Review of the Applications of Moringa oleifera Seeds Extract in Water Treatment. Civil and Environmental Research, 3, 1-9.

[13] Onyuka, J.H.O., Kakai, R., Arama, P.F. and Ofulla, A.V.O. (2013) Comparison of Antimicrobial Activities of Brine Salting, Chlorinated Solution and Moringa oleifera Plant Extracts in Fish from Lake Victoria Basin of Kenya. African Journal of Food, Agricultural, Nutrition and Development, 13, 7772-7788.

[14] Arnoldsson, E., Bergman, M., Matsinhe, N. and Persson, M.K. (2008) Assessment of Drinking Water Treatment by Using Moringa oleifera Natural Coagulant. Vattern, 64, 137-150.

[15] Folkard, G., Sutherland, J. and Shaw, R. (1999) Water Clarification Using Moringa oleifera Seed Coagulant. Waterlines, 17, 15-17.

[16] Adelaja, O.A., Amoo, I.A. and Aderibigbe, A.D. (2011) Biosorption of Lead Ions from Aqueous Solution Using Moring oleifera Pods. Archives of Applied Science Research, 3, 50-60.

[17] Vikashni, N., Matakite, M., Kanayathu, K. and Subramanium, S. (2012) Water Purification Using Moringa oleifera and Other Locally Available Seeds in Fiji for Heavy Metal Removal. International Journal of Applied Science and Technology, 2, 125-129.

[18] Meneghel, A.P., Affonso Jr., C.G., Fernanda, R., Douglas, D.C., Lindino, C.A. and Strey, L. (2013) Biosorption of Cadmium from Water Using Moringa (Moringa oleifera Lam.) Seeds. Water, Air, \& Soil Pollution, 224, 1383. http://dx.doi.org/10.1007/s11270-012-1383-2

[19] Alo, M.N., Anyim, C. and Elom, M. (2012) Coagulation and Antimicrobial Activities of Moringa oleifera Seed Storage at $3^{\circ} \mathrm{C}$ Temperature in Turbid Water. Advance in Applied Science Research, 3, 887-894.

[20] Sajidu, S.M., Henry, E.M.T., Kwamdera, G. and Mataka, L. (2005) Removal of Lead, Iron and Cadmium Ions by Means of Polyelectrolytes of the Moringa oleifera Whole Seed Kernel. WIT Transactions on Ecology and the Environment, 80.

[21] Ndibewu, P.P., Mnisi, R.L., Mokgalaka, S.N. and McCrindle, R.I. (2011) Heavy Metal Removal in Aqueous System Using Moringa oleifera: A Review. Journal of Material Science and Engineering, 6B, 843-853.

[22] Ali, E.N., Muyibi, S.A., Salleh, H.M., Md. Alam, Z. and Salleh, M.R.M. (2010) Production of Natural Coagulant from Moringa oleifera Seed for Application in Treatment of Low Turbidity Water. Journal of Water Resources and Protection, 2, 259-266. http://dx.doi.org/10.4236/jwarp.2010.23030

[23] Garcia-Fayos, B., Arnal, J.M., Verdu, G. and Sauri, A. (2010) Study of Moringa oleifera oil Extraction and Its Influence in Primary Coagulant Activity for Drinking Water Treatment. International Conference on Food Innovation.

[24] Amagloh, F.K. and Benang, A. (2009) Effectiveness of Moringa oleifera Seed as Coagulant for Water Purification. African Journal of Agricultural Research, 4, 119-123.

[25] Forster, S. (2000) Efficient Wastewater Treatment: The Field for Analytical and Monitoring Equipment. http://www.eco-web.com/edi/01759.html

[26] Suhartini, S., Hidayat, N. and Rosaliana, E. (2013) Influence of Powdered Moringa oleifera Seeds and Natural Filter Media on the Characteristics of Tapioca Starch Wastewater. International Journal of Recycling of Organic Waste in Agriculture, 2, 1-11.

[27] Mangale S.M., Chonde S.G., Jadhav A.S. and Raut, P.D. (2012a) Study of Moringa oleifera (Drumstick) Seed as Natural Absorbent and Antimicrobial Agent for River Water Treatment. Journal of Natural Product Plant Resource, 2, 89-100.

[28] Folkard, G. and Sutherland, T. (2001) The Use of Moringa oleifera Seed as a Natural Coagulant for Water and Wastewater Treatment. Department of Engineering, University of Leicester, Leicester.

[29] Muyibi, S.A., Bitima, A.H.M., Mohammed, T.A. and Megat Hohari, M.M.N. (2004) Conventional Treatment of Surface Water Using Moringa oleifera Seeds Extract as a Primary Coagulant. IIUM Engineering Journal, 5, 25-35.

[30] Subramanium, S., Vikashni, N., Matakite, M. and Kanayathu, K. (2011) Moringa oleifera and Other Local Seeds in Water Purification in Developing Countries. Research Journal of Chemistry and Environment, 15, 135-138.

[31] WHO (2006) Guideline for Drinking Water Quality (Electronic Resources): Incorporating First Addendum. Vol. 1, 3rd Edition.

[32] Mangale, S.M., Chonde, S.G. and Raut, P.D. (2012b) Use of Moringa oleifera (Drumstick) Seed as Natural Absorbent and an Antimicrobial Agent for Ground Water Treatment. Research journal of Recent Sciences, 1, 31-40.

[33] Sanchez-Martin, J., Beltran-Heredia, J. and Peres, J.A. (2012) Improvement of the Flocculation Process in Water 
Treatment by Using Moringa oleifera Seeds Extract. Brazilian Journal of Chemical Engineering, 29, 495-501. http://dx.doi.org/10.1590/S0104-66322012000300006

[34] Ghebremichel, K.A. (2004) Moringa Seed and Pumice as Alternative Natural Materials for Drinking Water Treatment. TRITA-LWR PHD 1013. 